\title{
Perspective Material for Photoenergetics on the Basis of Silicon with Binary Elementary Cells
}

\author{
M.K. Bakhadyrhanov ${ }^{1 *}$, U.X. Sodikov ${ }^{1}$, Kh.M. Iliev ${ }^{1}$, S.A. Tachilin ${ }^{1}$, Tuerdi Wumaier ${ }^{2}$ \\ ${ }^{1}$ Tashkent State Technical University,100095, Tashkent, Uzbekistan.bahazeb@yandex.com \\ ${ }^{2}$ Xinjiang Institute of Engineering, 830023,Urumchi, China.turdi@ms.xjb.ac.cn \\ *Correspondence: bahazeb@yandex.com
}

\begin{abstract}
The paper proposes a scientifically-grounded, principally-new approach to managing the fundamental parameters of the basic material of electronic engineering as like silicon. The essence of the proposed approach is the formation of binary elementary cells in the silicon lattice involving elements III (B, Al, Ga, Zn) and V (P, As, Sb) groups in the form of $\mathrm{Si}_{2} \mathrm{GaAs}, \mathrm{Si}_{2} \mathrm{GaSb}$, etc. Taking electrical and chemical parameters of these impurity atoms into account, as well as their diffusion parameters in $\mathrm{Si}$, the formation is determined by the most suitable pairs of atoms of groups III and $\mathrm{V}$ that allow obtaining silicon with the necessary composition and structure of binary elementary cells, as well as their more complex associations, up to the formation of nanocrystals of semiconductor connections $\mathrm{A}^{\mathrm{III}} \mathrm{B}^{\mathrm{V}}$. It is shown that by controlling the composition, structure and concentration of binary elementary cells, it is possible to significantly expand the spectral sensitivity of silicon, both in the IR and $h \lambda>E g$ directions. The formation of nanoclusters of $\mathrm{A}^{\mathrm{III}} \mathrm{B}^{\mathrm{V}}$ semiconductor compounds in the silicon lattice significantly changes the emissivity of the material. It is established that the successive diffusion of elements of groups III and V in silicon and additional lowtemperature annealing under certain thermodynamic conditions make it possible to ensure the maximum participation of the impurity atoms introduced in the formation of binary elementary cells. Silicon with binary elementary cells involving atoms of groups III and V is a new class of semiconductor material with unique functionality for modern optoelectronics and photoenergetics.
\end{abstract}

Keywords: Semiconductor; Binary clusters; Muticascade PV Cells; Elementary Cells; Self-Organization; SelfStructure; Nanostructure; Nanocrystal; Photosensivity; Combinations; Multistage PV cells

\section{Received: Nov 24, 2018 Accepted: Dec 26, 2018 Online: Jan 13, 2019}

\section{Introduction}

The main problem facing modern photoenergetics is an increase in the efficiency of silicon photovoltaic cells ${ }^{[1-2]}$. It is this factor that determines their prices and large-scale ground-based use in photoenergetics. The main reason for this is not only the participation in the photogeneration of a significant part of the solar IR radiation in the region $\lambda=1$.15-3 $\mu \mathrm{m}$, which is about $40 \%$ of the solar radiation, but also the ineffective use of photon energy from the energy hv> Eg, which causes thermolysis, i.e. to the deterioration parameters of the photovoltaic (PV) cells. According to previous studies ${ }^{[3]}$, in optical silicon cells the optical losses associated with the above effects are about $50 \%$.

However, the existing technology and functionality of semiconductor materials, including silicon, which is now widely used in photoenergetics, do not provide a solution. The recent use of multi-cascade PV cells based on semiconductor compounds $\mathrm{A}^{\mathrm{III}} \mathrm{B}^{\mathrm{V}}{ }^{[4]}$ cannot substantially solve the problem of large-scale use of such PV cells in terrestrial conditions due to rather complicated technological conditions of their manufacturing and the high cost.

Therefore, a successful solution of this problem requires the substantiation of the physical foundations and the development of technological conditions that allow the spectral region of silicon sensitivity to be expanded both in the direction of the IR region and in the direction of the visible and UV spectral regions. In this paper we proposed an original solution to this problem, consisting in a substantial expansion of the spectral region of silicon sensitivity, as a

Copyright (C) 2019 M.K. Bakhadyrhanov et al. This is an Open Access article distributed under the terms of the Creative Commons AttributionNonCommercial 4.0 International License (http://creativecommons.org/licenses/by-nc/4.0/), permitting all non-commercial use, distribution, and reproduction in any medium, provided the original work is properly cited. 
result of the formation of fundamentally new elementary cells participating atoms of groups III and V in the silicon lattice. It should be noted that such new elementary cells act as a new class of quantum structures with unique and yet unexplored functionalities with a managed compose, structure, concentration, and distribution in the silicon lattice.

\section{Materials and Methods}

As is known, elements of III- and V-groups in silicon under the condition of doping separately are mainly located at the centers of the crystal lattice, form solid substitutional solutions and act as donors and acceptors, respectively (Figure 1). Hence, these impurities are technological impurities and are widely used in the preparation of both n- and p-type conductivity materials with different resistivities. The main electrical and diffusion parameters of these atoms are given in Table $1^{[5]}$.

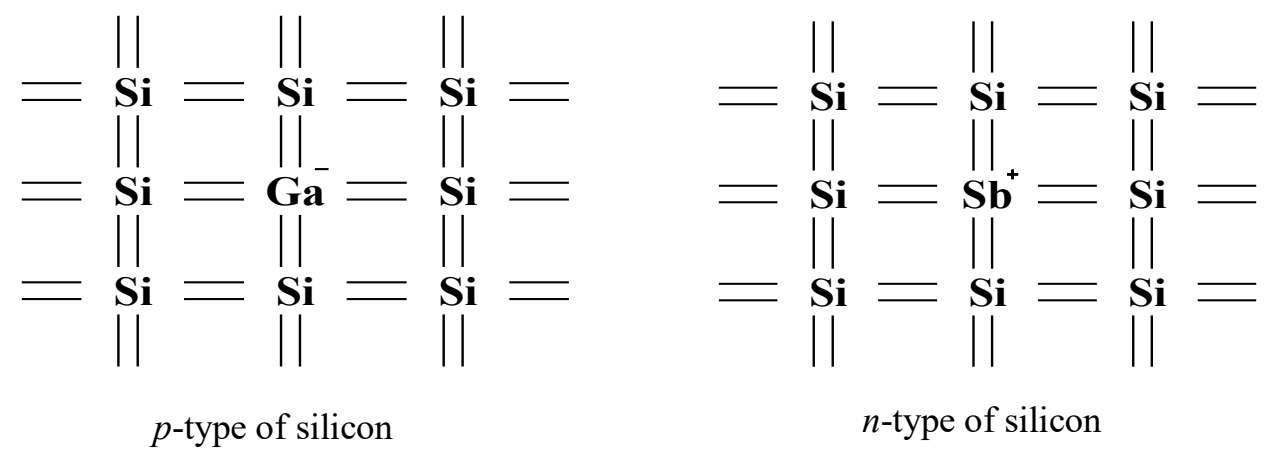

Figure 1. Elements of III and V-groups in silicon.

\begin{tabular}{|c|c|c|c|c|c|c|}
\hline Element & $\begin{array}{c}\text { Radius of } \\
\text { atom } \mathrm{r}_{\mathrm{a}}, \AA\end{array}$ & $\begin{array}{c}\text { Covalent } \\
\text { radius } \mathrm{r}_{\mathrm{K}}, \AA\end{array}$ & $\begin{array}{c}\text { Electro- } \\
\text { negativity }\end{array}$ & $\begin{array}{c}\text { Coefficient of } \\
\text { diffusion } \mathrm{sm}^{2} / \mathrm{s} \\
\text { at } 1200{ }^{\circ} \mathrm{C}\end{array}$ & $\begin{array}{c}\text { Max. } \\
\text { solubility } \\
\mathrm{sm}^{-3}\end{array}$ & $\begin{array}{c}\text { Outer of } \\
\text { electron shell } \\
\text { of the atoms }\end{array}$ \\
\hline $\mathrm{B}$ & 0.83 & 0.88 & 2.04 & $1 \times 10^{-12}$ & $>1 \times 10^{20}$ & $2 \mathrm{~s}^{2} 2 \mathrm{p}^{1}$ \\
$\mathrm{Al}$ & 1.43 & 1.25 & 1.51 & $4 \times 10^{-11}$ & $>1 \times 10^{20}$ & $3 \mathrm{~s}^{2} 3 \mathrm{p}^{1}$ \\
$\mathrm{Ga}$ & 1.22 & 1.25 & 1.81 & $1 \times 10^{-11}$ & $5 \times 10^{19}$ & $4 \mathrm{~s}^{2} 4 \mathrm{p}^{1}$ \\
$\mathrm{In}$ & 1.62 & 1.50 & 1.78 & $3 \times 10^{-12}$ & $1 \times 10^{19}$ & $5 \mathrm{~s}^{2} 5 \mathrm{p}^{1}$ \\
$\mathrm{P}$ & 1.15 & 1.00 & 2.19 & $1 \times 10^{-12}$ & $>1 \times 10^{20}$ & $3 \mathrm{~s}^{2} 3 \mathrm{p}^{3}$ \\
$\mathrm{As}$ & 1.25 & 1.21 & 2.18 & $4 \times 10^{-13}$ & $>1 \times 10^{20}$ & $4 \mathrm{~s}^{2} 4 \mathrm{p}^{3}$ \\
$\mathrm{Sb}$ & 1.82 & 1.41 & 2.05 & $1 \times 10^{-12}$ & $1 \times 10^{20}$ & $3 \mathrm{~s}^{2} 3 \mathrm{p}^{3}$ \\
$\mathrm{Bi}$ & 1.55 & 1.52 & 2.02 & $1 \times 10^{-13}$ & $5 \times 10^{17}$ & $6 \mathrm{~s}^{2} 6 \mathrm{p}^{3}$ \\
$\mathrm{Si}$ & 1.17 & 1.17 & 1.90 & $1 \times 10^{-14}$ & $5 \times 10^{22}$ & $3 \mathrm{p}^{2} \mathrm{~s}^{2}$ \\
\hline
\end{tabular}

Table 1. Electrical and diffusion parameters of crystal lattice atoms.

Studies carried out over the last 10-15 years showed that the most effective way of forming clusters of impurity atoms, including binary ones, was the low-temperature doping with subsequent heat treatment under certain thermo-dynamic conditions, depending on the nature of the impurity atoms ${ }^{[6-10]}$. In contrast to traditional high-temperature diffusion, as well as epitaxial methods, the proposed method allows the maximum participation of impurity atoms in the formation of binary elementary cells with a controlled structure, compose, concentration and distribution in the silicon lattice ${ }^{[11-}$ ${ }^{12]}$. A high solubility and a sufficiently low diffusion coefficient of the elements of groups III and V in silicon provide a layer of the necessary thickness enriched in such cells in the volume of the crystal, i.e. the problem of obtaining a new class of a volume-nanostructure silicon with managed parameters is practically solved.

To form new elementary cells, the atoms of groups III and V should be adjacent and occupy two adjacent site positions in the silicon lattice, forming electrically neutral molecules $\left(\mathrm{A}^{+}{ }_{\mathrm{III}} \mathrm{B}_{\mathrm{V}}^{-}\right)$, which are the basis for new and yet unexplored elementary $\mathrm{Si}_{2} \mathrm{~A}^{+}{ }_{\mathrm{III}} \mathrm{B}_{\mathrm{V}}^{-}$cells (Figure 2). In such cells there will be a partially-ionic covalent bond formed by such lattices that practically does not violate the tetrahedral bond and they form part of the crystal lattice of silicon. This provides a more advantageous thermodynamic state of the system, than when these atoms are in atomic states (Figure 2b), which stimulates self-organization, self-restructure and the formation of other new elementary cells. 

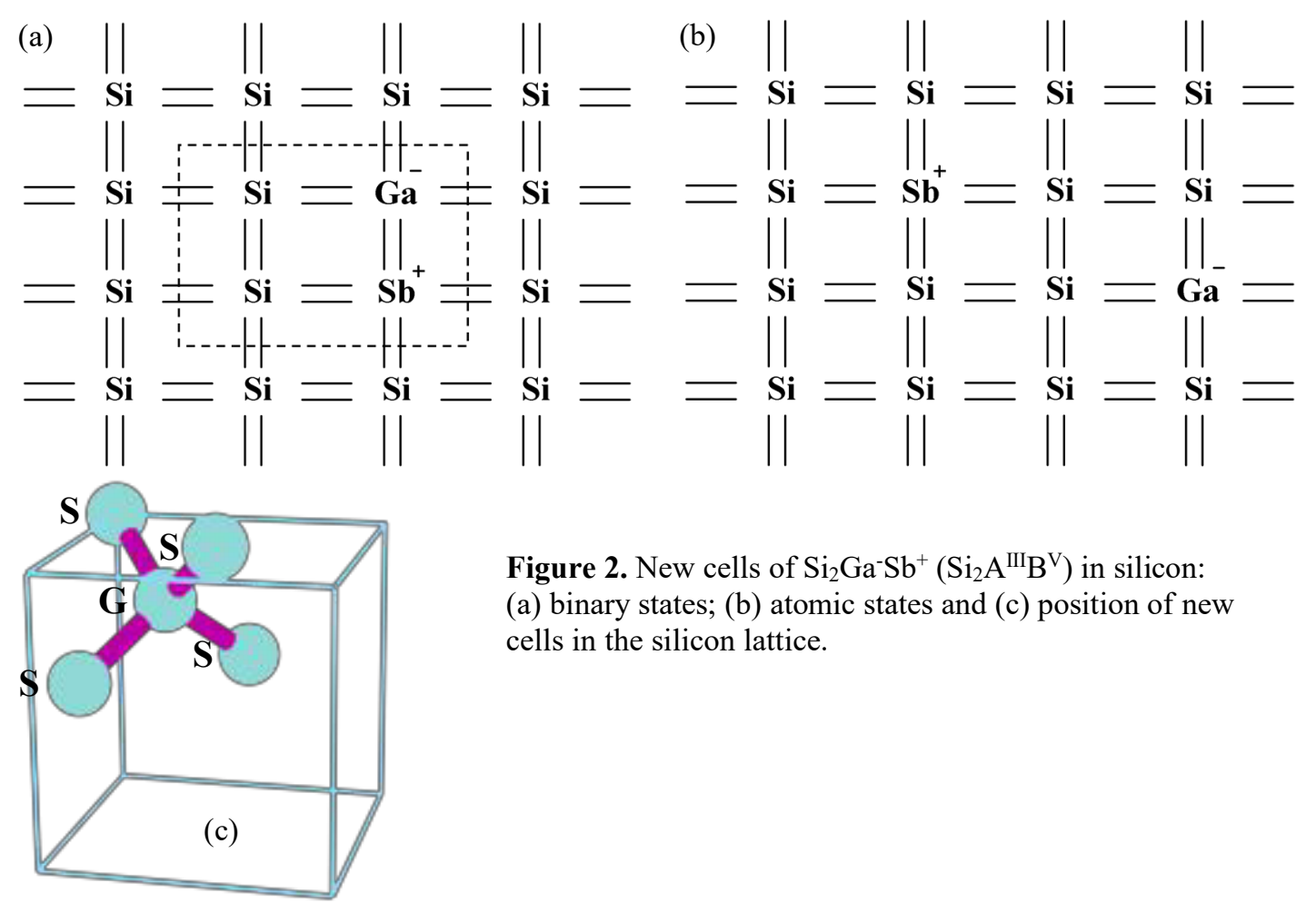

Figure 2. New cells of $\mathrm{Si}_{2} \mathrm{Ga}^{-} \mathrm{Sb}^{+}\left(\mathrm{Si}_{2} \mathrm{~A}^{\mathrm{III}} \mathrm{B}^{\mathrm{V}}\right)$ in silicon: (a) binary states; (b) atomic states and (c) position of new cells in the silicon lattice.

As the results of the study showed, with the increase in the concentration of impurity atoms being introduced, molecules are formed with the formation of more complex structures (Figure 3), eventually forming nuclei of a new phase of the semiconductor compound, i.e., formation of nanocrystals of semiconductor compounds $A^{\mathrm{III}} \mathrm{B}^{\mathrm{V}}$ in the silicon lattice (Figure 4). Since the newly formed nanostructures are in the silicon lattice, the fundamental parameters of silicon with such nanostructures differ significantly not only from the fundamental parameters of silicon, but also from the corresponding semiconductor compounds $\mathrm{A}^{\mathrm{III}} \mathrm{B}^{\mathrm{V}}$ (Table 2) ${ }^{[13-14]}$, which is a unique feature of such materials.

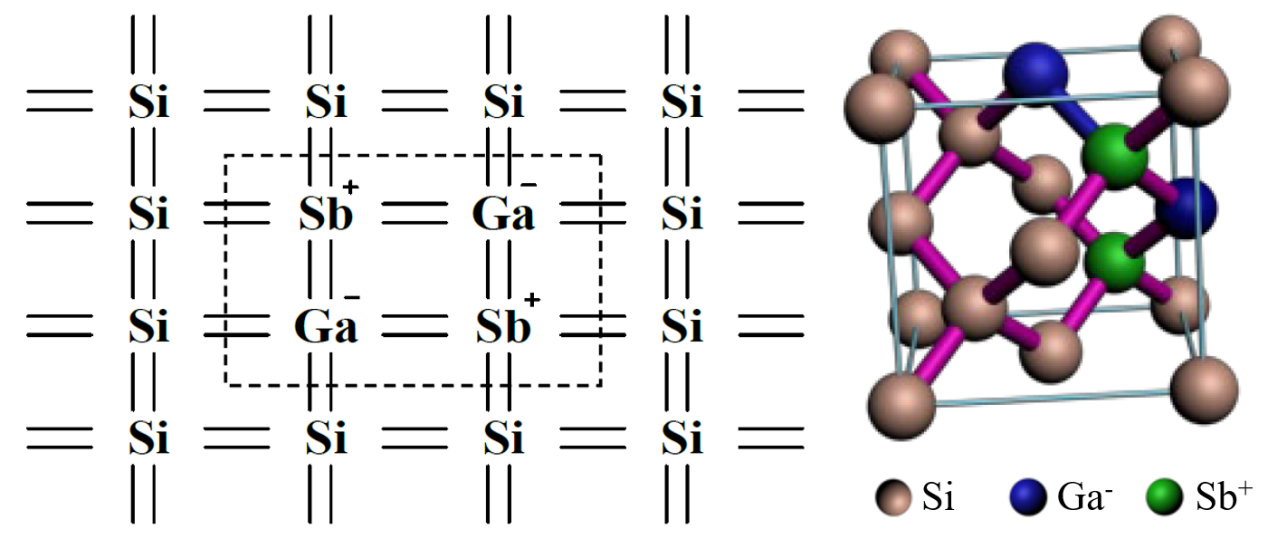

Figure 3. New elementary cells $\mathrm{A}^{\mathrm{III}} \mathrm{B}^{\mathrm{V}}\left(\mathrm{Ga}^{-} \mathrm{Sb}^{+}\right)$in silicon.

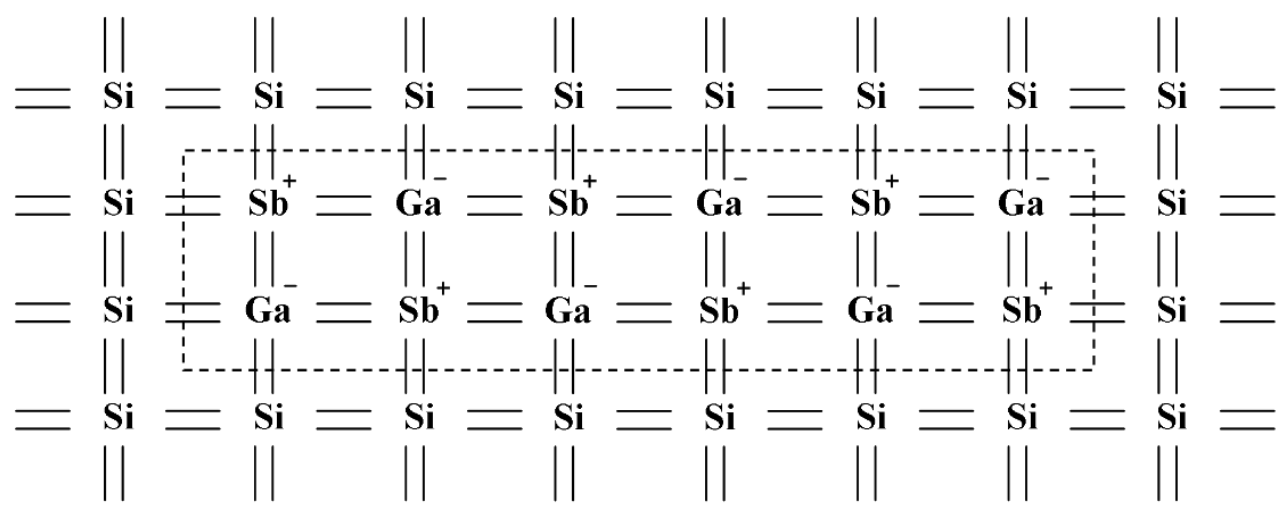

Figure 4. Hanocrystal $\mathrm{A}^{\mathrm{III}} \mathrm{B}^{\mathrm{V}}\left(\mathrm{Ga}^{-} \mathrm{Sb}^{+}\right)$in the lattice of silicon. 


\begin{tabular}{|c|c|c|}
\hline Semiconductor & $E_{g},{ }$ B & Mobility of electrons, $\mathrm{sm}^{2} /(\mathrm{V} \cdot \mathrm{s})$ \\
\hline $\mathrm{InSb}$ & 0.18 & 100,000 \\
\hline $\mathrm{InAs}$ & 0.36 & 30,000 \\
\hline $\mathrm{InP}$ & 1.26 & 4,600 \\
\hline $\mathrm{GaSb}$ & 0.73 & 5,000 \\
\hline $\mathrm{GaAs}$ & 1.42 & 9,000 \\
\hline $\mathrm{GaP}$ & 2.26 & 110 \\
\hline $\mathrm{AlSb}$ & 1.65 & 200 \\
\hline $\mathrm{AlP}$ & 2.50 & ---- \\
\hline $\mathrm{Si}$ & 1.12 & 1,300 \\
\hline
\end{tabular}

Table 2. Fundamental parameters of the newly formed silicon nanostructure.

This means that we get the simplest way of a new type of material - an integral material with a given modulated bandgap width (Figure 5). Therefore, silicon with new elementary cells involving atoms of groups III and V and their associations on the one hand can absorb a rather wide spectrum of radiation, both in the IR region and in the visible and UV regions. It should be noted that the absorption of light in such materials can occur through direct interband transitions, since the atoms of elements III and V of the group in this case act not as alloying impurities, but enter the basis of new elementary cells. And on the other hand, there is no less important property, it is the possibility of changing the band structure of silicon from the indirect to the straight-band (Figure 6). The straight-bandedness of nanocrystals is the key to their high photosensitivity in a wide spectral range.

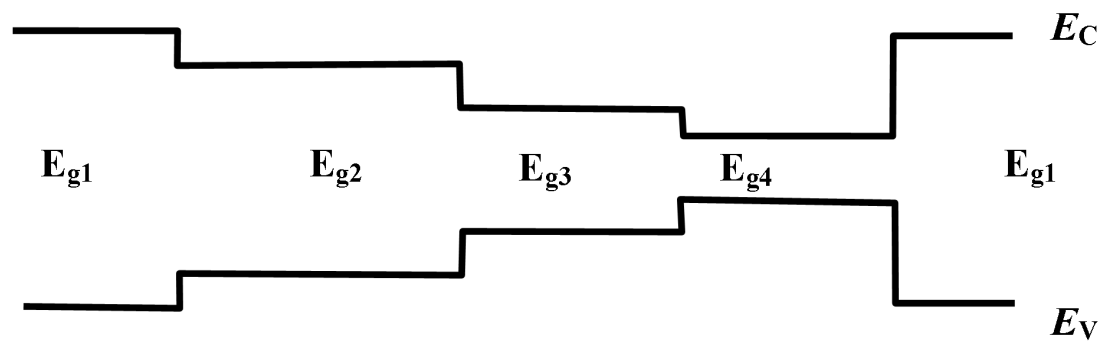

Figure 5. Prospective band structure of silicon with various elementary cells.

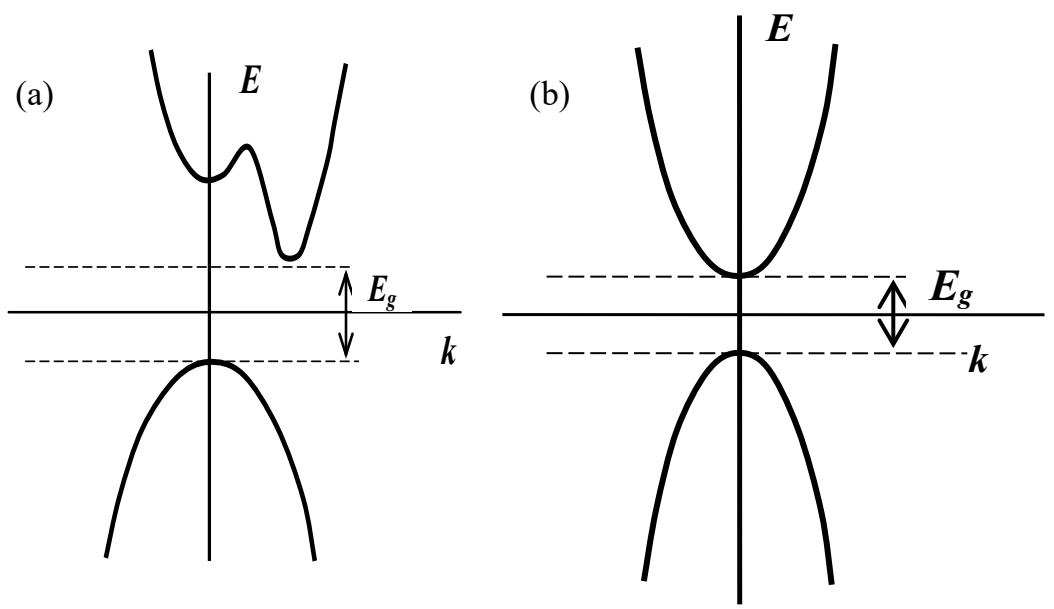

Figure 6. (a) Conventional indirect band structure of silicon; (b) Band structure of nanocrystal of type $\mathrm{A}^{\mathrm{III}} \mathrm{B} \mathrm{V}$ in the silicon lattice, but like as direct band gap.

\section{Results}

A question arises: Is it possible to form elementary cells of all semiconductor compounds $\mathrm{A}^{\mathrm{III}} \mathrm{B}^{\mathrm{V}}$ in silicon with the participation of all the atoms of groups III and V? Yes, theoretically and physically possible, but for this it is necessary to fulfill the following conditions ${ }^{[15-16]}$ :

1. $|\Delta Z|=2 Z_{S i}-\left(Z_{I I I}+Z_{V}\right) \leq 0,2 Z_{S i}$

where $Z_{S i}$ is the covalent radius of the silicon atom, $Z_{I I I}$ and $Z_{V}$ are the covalent radius of the atoms of group III and $\mathrm{V}$. 
2. The electronegativity of the III and V atoms of the group should be sufficiently close to the electronegativity of the silicon atoms.

3. The sum of the valence electrons of two neighboring impurity atoms at the sites of the crystal lattice of silicon should be 8 .

4. $\quad r_{m} \leq 100 R$

where $r_{m}$ is the distance between the atoms of group III and V separately, and also between them after diffusion doping, and $\mathrm{R}$ is the lattice constant of silicon $(5.4 \AA)$.

The fulfillment of the conditions 1-3 is determined by the parameters of the impurity atoms, and the fourth condition is determined by the diffusion alloying conditions. Analysis of the data given in Table 3 shows that the main criterion for the formation of unit cells with the participation of atoms of groups III and V is condition 1, since condition 3 for these impurities is automatically satisfied, and condition 2 is satisfied for most impurity atoms.

Table 3 shows the fulfillment of condition 1 for all possible combinations of pairs of formation of new elementary cells involving all atoms of groups III and V. As can be seen from Table 3, all possible combinations can be divided into the following main groups:

1. The most suitable combinations are BBi, AlP, GaP.

2. Suitable combinations are BSb, AlAs, GaAs.

3. Moderately suitable combinations - BAs, GaSb, InP.

4. Unsuitable - other combinations.

\begin{tabular}{|c|c|c|c|c|c|c|c|}
\hline $\mathbf{A}^{\mathrm{III}} \mathbf{B}^{\mathrm{v}}$ & $\mathbf{r}_{I I I}+\mathbf{r v}_{\mathrm{V}}, \AA$ & $\Delta \mathbf{r}, \AA$ & Group & $\mathbf{A}^{\mathrm{III}} \mathbf{B}^{\mathrm{v}}$ & $\mathbf{r}_{\text {III }}+\mathbf{r v}_{\mathrm{V}}, \AA$ & $\Delta \mathbf{r}, \AA$ & Group \\
\hline BP & 1.98 & 0.36 & 4 & $\mathrm{GaP}$ & 2.35 & 0.01 & 1 \\
\hline BAs & 2.09 & 0.25 & 3 & GaAs & 2.46 & 0.12 & 2 \\
\hline $\mathrm{BSb}$ & 2.29 & 0.15 & 2 & $\mathrm{GaSb}$ & 2.66 & 0.32 & 3 \\
\hline $\mathrm{BBi}$ & 2.38 & 0.06 & 1 & $\mathrm{GaBi}$ & 2.77 & 0.43 & 4 \\
\hline AlP & 2.35 & 0.01 & 1 & InP & 2.60 & 0.26 & 3 \\
\hline AlAs & 2.46 & 0.12 & 2 & InAs & 2.76 & 0.42 & 4 \\
\hline $\mathrm{AlSb}$ & 2.66 & 0.32 & 4 & $\mathrm{InSb}$ & 2.96 & 0.62 & 4 \\
\hline AlB1 & 2.77 & 0.43 & 4 & InBi & 3.02 & 0.68 & 4 \\
\hline $\mathrm{Si}-\mathrm{Si}$ & 2.34 & 0 & - & & & & \\
\hline
\end{tabular}

Table 3. Distance of atoms of group III and V in a silicon nanostructure.

\section{Discussion}

Thus, with the participation of elements 1 and 2 of the combination group, not only the known cells of $\mathrm{A}^{+}{ }_{\mathrm{III}} \mathrm{B}_{\mathrm{V}}^{-}$semi- $^{-}$ conductor compounds can be formed, but also the nonexistent as BAs, BSb, and BBi. This opens up wide opportunities for managing the fundamental parameters of silicon and gives rise to a new scientific direction in the field of semiconductor materials science, i.e. obtained materials of a given controlled band structure.

To confirm our assumption, theoretical calculations are needed on the one hand to determine the fundamental parameters of a new crystal lattice, depending on their composition, structure and size, and on the other hand, it is necessary to develop an optimal technology for obtaining samples containing the maximum concentration of the above elementary cells, careful experimental studies of the electrical, optical, photoelectric properties of the obtained samples and microscopic studies to lead identify functionality of such materials. It is also necessary to develop an optimal technology for manufacturing PV cells based on such structures.

At present, we have conducted preliminary experiments on the formation of GaP elementary cells in a silicon lattice, showing an increase in the spectral sensitivity toward the IR region of the light emission spectrum to $3.5 \mu \mathrm{m}$. Based on such materials, PV cells are made. It is established that in the produced PV cells starting from $3.5 \mu \mathrm{m}$ there is a significant increase in the short-circuit current and the idling voltage. These data indicate that it is possible to create $\mathrm{PV}$ cells with characteristics similar to multi-stage solar cells based on $\mathrm{A}^{\mathrm{III}} \mathrm{B}^{\mathrm{V}}$ [17-21]. 


\section{Conclusion}

The formation of new elementary cells involving elements of groups III and V and their associations in the silicon lattice is the discovery of a new scientific direction in semiconductor materials science to obtain a fundamentally new semiconductor material with unique functional capabilities.

This means that in the near future on the basis of silicon with binary nanoclusters it is possible to create multistage "silicon" PV cells replacing costly multistage PV cells based on semiconductor compounds $\mathrm{A}^{\mathrm{III}} \mathrm{B}^{\mathrm{V}}$ and $\mathrm{A}^{\mathrm{II}} \mathrm{B}^{\mathrm{VI}}$.

\section{Acknowledgement}

This work was sponsored by Science and Technology projects PROJECT PROPOSAL FOR UZBEK-CHINA RESEARCH PROGRAM, "National Key R\&D Program of China”, No. 2016 YFE0120900.

\section{References}

1. Tonio Buonassisi/Introduction to fundamentals of photovoltaics/ocw.mit.edu

2. Ch. P. Poole, Jr. F. J. Owens/Introduction to nanotechnology/Publsh. by J. Wiley \& Sons, Inc. Hoboken. New Jersey/USA, 2003.

3. Alan II., Fahrenbruch, Richard H. Bube/Fundamentals of solar cells/Photovoltaic solar energy conversion/New York, 1998.

4. Ж.И. Алферов/Избранные труды нанотехнологии/Издательский дом Магистр-пресс, Москва, 2011.

5. J. Emsley/The elements/ Clarendon Press, Oxford, 1991.

6. M.G. Milvidskii, V.V. Chaldishev/Nanoscale atomic clusters in semiconductors as a new approach to formation of materials properties/Semiconductors, 1998, No 5.pp. 513-522.

7. T. Sekuguchi, S. Yoshida, K.M. Itoh/Self-assembly of parallel atomic wires and periodic clusters of silicon on a vicinal Si(111) surface/Phys.Rev.Lett.95, 106101 (2005).

8. F.F. Komarov, O.I. Velichko, V.A. Dobrushkin, A.M. Mironov/Mechanisms of arsenic clustering in silicon/Phys. Rev. B. Vol.74 (3), Art. no. 035205 (2006).

9. Chuanyun Xiao, Jessica Blundell, Frank Hagelberg and William A., Lester J./Silicon clusters doped with an yttrium metal atom impurity/International Journal of Quantum Chemistry, Vol 96, Issue 4, pages 416-425, 2004.

10. M.K. Bakhadyrhanov, K.S. Aypov, Kh.M. Iliev, G.Kh. Mavlonov, and O.E. Sattorov/Effect of electric field, illumination, and temperature on the negative magnetoresistance of low-temperature-diffusion-doped silicon/Technical Physics Letters, 2009, Vol. 35, No. 8, pp 741-744.

11. M.K. Bakhadyrhanov, Sh.I. Askarov, and N. Norkulov/Some features of chemical interaction between a fast diffusing impurity and a group VI element in silicon/Phys. stat. sol. (a) 142, 339 (1994).

12. M.K. Bakhadyrhanov, K.S. Aypov, G.Kh. Mavlonov, and S.B. Isamov/Negative magnetoresistance in silicon with manganese-atom complexes [Mn] /Semiconductors, 2010, Vol. 44, No. 9. pp. 1145-1148.

13. C. Hilsum, A.C. Rose-innes/Semiconducting III-V compounds/Oxford, London, 1961.

14. R. K. Wilardson, H. L. Goering/Compound semiconductors preparation of III-V compounds/Chapman\&Hall, Ltd., London, 1965.

15. M.S. Saidov/Concentrated semiconductor solid solutions of compounds and possibility of realization in-band-cascade devices/Applied Solar Energy, 2001, 1, p. 3-9.

16. M.S. Saidov/The possibility of the formation of continuous solid solutions of silicon and germanium with compounds with defective diamond-like structures/ Applied Solar Energy, 2002, 2.

17. B.A. Abdurakhmanov, M.K.Bakhadyrhanov, K.S. Aypov, H.M. Iliev, E.B. Saitov, A. Mavlonov, U.H. Kamalov/Formation of clusters of impurity atoms of nickel in silicon and controlling their parameters/Nanosciens and nanotechnology, 2014, 4(2): 23-26.

18. M.K. Bakhadyrhanov and S.B. Isamov/IR Photodetectors operating under background illumination/Technical Physics, 2016, Vol. 61, No 3., pp. 458-460.

19. Z.A. Yunusov, Sh.U. Yuldashev, Kh. T. Igamberdiev, Y.H. Kwos and T.W. Kang M.K.Bakhadyrhanov, S.B. Isamov and N.F. Zikrillaev/Journal of the Korean Physical Society, Vol. 64, No. 10, May 2014, pp. 1461-1465.

20. M. K. Bakhadyrkhanov, A. Sh. Mavlyanov, U. Kh. Sodikov, and M. K. Khakkulov/Silicon with Binary Elementary Cells as a Novel Class of Materials for Future Photoenergetics/Applied Solar Energy, 2015, Vol. 51, No. 4, pp. $258-261$.

21. M.K. Bakhadyrhanov, S.A. Valiev, N.F. Zikrillaev, S.V. Kaveshnikov, E.B. Saitov, and S.A. Tachilin/Silicon photovoltaic cells with clusters of nickel atoms/Applied solar energy, 2016, Vol. 52, No 4, pp. 278-2 